Discussion Paper No. 886

\title{
GENERAL EQUILIBRIUM DYNAMICS WITH NAIIVE AND SOPHISTICATED HYPERBOLIC CONSUMERS IN AN OVERLAPPING GENERATIONS ECONOMY
}

\author{
Takeshi Ojima
}

September 2013

The Institute of Social and Economic Research Osaka University

6-1 Mihogaoka, Ibaraki, Osaka 567-0047, Japan 


\title{
General equilibrium dynamics with naïve and sophisticated hyperbolic consumers in an overlapping generations economy*
}

\author{
Takeshi Ojima ${ }^{\dagger}$ \\ Graduate School of Economics, Osaka University \\ and \\ The Institute of Social and Economic Research, Osaka University
}

August 5, 2013

${ }^{*}$ I am deeply indebted to Shinsuke Ikeda for invaluable guidance through my research. I also thank to Kouichi Futagami, Takeo Hori, and Tatsuro Iwaisako for their comments and advice. All remaining errors are mine. The author declares that he has no relevant or material financial interests that relate to the research described in this paper.

${ }^{\dagger}$ The Institute of Social and Economic Research, Osaka University, 6-1 Mihogaoka, Ibaraki, Osaka 567-0047, Japan. Email address: ojima@iser.osaka-u.ac.jp 


\begin{abstract}
Using an overlapping generations model, this paper describes interactions between naïve and sophisticated hyperbolic discounters in general equilibrium. The naïfs, who overestimate their future propensity to save and hence over-forecast the future equilibrium asset prices, are exploited through capital transactions by sophisticates, who correctly forecast the future asset prices by incorporating the naifs' mis-forecasts. Due to the capital losses, the naiffs fall into bankruptcy when they are highly present-biased, highly patient, and having a low population density. Under generous conditions, the equilibrium is shown to be globally stable and Pareto inefficient in the ex-post sense.
\end{abstract}

Keywords: Bankruptcy; Hyperbolic discounting; Naïf; Sophisticate; General equilibrium.

JEL classification : D51, D91 


\section{Introduction}

The self-control problem under hyperbolic discounting produces suboptimal saving/consumption behavior (e.g., Krusell et al., 2002; Laibson, 1997). In the context of general equilibrium, it would not be the whole story. Naïve hyperbolic discounters, who are not aware of their own self-control problem, will overestimate the economy's future propensity to save and hence future asset returns. Sophisticates, who are aware of the effect of the self-control problem, will lend to naïfs at high interest rates that equal overestimated future returns on assets. ${ }^{1}$ By using the borrowed money, naïfs buy less profitable assets than they expect. From the transactions, sophisticates would obtain excess returns, whereas naïfs would suffer capital losses and possibly fall into bankruptcy, as casually observed in the unsecured consumer loan markets. A comprehensive understanding of such naïf-sophisticate interactions requires dynamic general equilibrium analysis.

This is the first study to analyze dynamic general equilibrium with interactions between naïve and sophisticated hyperbolic consumers. ${ }^{2}$ By solving the general equilibrium system in an overlapping generations model, I obtain equilibrium price dynamics in a closed form. The equilibrium is then characterized in terms of unique existence, global stability, and Pareto inefficiency. It is shown that the naif-sophisticate interaction that is conjectured at the outset is indeed supported as equilibrium phenomena.

In this equilibrium, naïfs' mis-forecasting plays a critical role. Naïve hyperbolic consumers overestimate the economy's future propensity to save and hence future asset returns even if their expectations are consistent with the (believed) structure of the economy. The naïfs' expectation errors produce excess returns for sophisticates

\footnotetext{
${ }^{1}$ Definitions of naïs and sophisticates originate from O’Donoghue and Rabin (1999).

${ }^{2}$ An overlapping generations model of a dynamic economy inhabited by sophisticates is analyzed by many studies (e.g., Barro, 1999; Krusell et al., 2002; Sorger, 2007).
} 
and capital loss for naïfs. This equilibrium exploitation process is shown by first solving the naifs' expectation dynamics and substituting the result into the general equilibrium system.

The equilibrium with the naïfs' mis-forecasting has a couple of unique properties. First, the steady-state interest rate on non-dividend assets is higher than the population growth rate (zero in this paper). This contrasts with the case of the standard monetary overlapping generations model, in which the steady-state interest rate equals the population growth rate (see, e.g., Samuelson, 1958, and Tirole, 1985).

Second, present bias affects portfolio selection. In particular, naïfs' portfolios are shown to differ from those of sophisticates. Previous studies of behavioral economics show that present-bias does not affect portfolio selection (see, e.g., Luttmer and Mariotti, 2003).

I find that in my model naïfs are likely to fall into bankruptcy (i) when the degree of present-bias is high, and hence the naïfs overestimates the future asset price seriously, (ii) when the sophisticate-naïf population ratio is high, and hence each naïf borrows heavily from a number of sophisticate lenders, and (iii) when the long-run discount factor is high, so that the present bias is serious. ${ }^{3}$

This research relates to the previous literature as follows. Gabrieli (2011) analyzes competitive equilibriums with hyperbolic consumers. He shows the important result that in no equilibrium do naïfs have perfect foresight. However, he does not analyze interactions of naïfs and sophisticates. My study challenges this problem. Heidhues and Koszegi (2010) theoretically explain the relationship between naïfs and sophisticates. Using contract theory, they show that naifs are exploited by firms in the credit market. In contrast, I show that in a general equilibrium naïfs suffer

\footnotetext{
${ }^{3}$ Meier and Sprenger (2010) empirically show that high present-biased individual have high amounts of credit card debt.
} 
capital losses caused by borrowing at market interest rates higher than the asset return.

The remainder of the paper is structured as follows. The model is set up in Section 2. In Section 3, I discuss a no-bankruptcy equilibrium. I clarify the parameter condition that determines whether naïfs fall into bankruptcy. Section 4 presents the debt adjustment method that underlies a bankruptcy economy and presents a bankruptcy equilibrium. Section 5 shows that both the no-bankruptcy and the bankruptcy economy are inefficient. Finally, the conclusions are presented in Section 6.

\section{Model}

Consider an overlapping generations economy starting from $t=0$. Consumers live for three periods: young, middle-aged, and old. The population is constant and normalized as one. Consumers are quasi-hyperbolic, and hence faced with the selfcontrol problem that the preference for a large reward with a long delay over a smaller reward with a shorter delay will be reversed as time passes. Two types of consumers coexist in this economy: sophisticates, who are aware of their selfcontrol problem and incorporate it into their decision making, and naïs, who are not aware of their self-control problem and, hence, do not incorporate the future preference reversal into their decisions. The population ratio of sophisticates to naïs is $m$ to one, implying that the population is $m /(1+m)$ for sophisticates and $1 /(1+m)$ for naïfs.

I assume one perishable consumption good $c$ and one asset $a$, which consumers cannot short. By considering the consumption good as a numeraire, I represent the time- $t$ asset price by $p_{t}$. The asset is an outside asset, the total amount of which equals a constant, $A$. Consumers can borrow and lend in the loan market 
at a competitive gross rate of interest, $R_{t}$. Let $s$ denote the amount of lending, a negative $s$ indicating borrowing. Consumers are endowed with $w$ units of the good only when they are young.

Consumers' intertemporal preferences are characterized by quasi-hyperbolic discounting: the discount factor is given by a $(\beta, \delta)$ model, where $\delta \in(0,1]$ represents the long-run discount factor and $\beta \in(0,1)$ represents present bias. Exponential discounting is a special case in which beta equals one. Because of the discounting feature, consumers are faced with the self-control problem in which they have to regulate their lifetime behavior under time inconsistency. Let me formulate the utility-maximization problems separately for sophisticates, who are cognizant of the self-control problem, and for naïfs, who are not.

\subsection{Sophisticates' problem}

Sophisticates solve their problem backwardly. First, with the net wealth at beginning of the given mid-age, the consumers solve middle-aged problem. Second, with the optimal behavior of their middle-aged selves being given, sophisticates maximize the entire lifetime utility. For simplicity, I specify period utility by the logarithmic function, and make the following assumption.

Assumption 1. Sophisticates have perfect foresight. 
The middle-aged sophisticates' problem (MSP) is described as follows:

$$
\max _{c_{S, t, t+1}, c_{S, t, t+2}, S_{S, t, t+1}, a_{S, t, t+1}} \ln c_{S, t, t+1}+\beta \delta \ln c_{S, t, t+2}
$$

s.t. $\quad c_{S, t, t+1}+s_{S, t, t+1}+p_{t+1} a_{S, t, t+1} \leq R_{t} s_{S, t, t}+p_{t+1} a_{S, t, t}$,

$$
c_{S, t, t+2} \leq R_{t+1} s_{S, t+1}+p_{t+2} a_{S, t, t+1},
$$

$$
0 \leq a_{S, t, t+1} \leq A
$$

$$
s_{S, t, t}, a_{S, t, t} \text { given, }
$$

where $c_{S, t, t+i}$ represents the time $t+i$ consumption of sophisticates in generation $t$, etc.

Equations (2) and (3) represent flow budget constraints for the middle-aged and the old, respectively. Equation (4) represents the short-sales constraint. I represent the optimal consumption as functions of $s_{S, t, t}, a_{S, t, t}$, i.e., $c_{S, t, t+1}\left(s_{S, t, t}, a_{S, t, t}\right)$, $c_{S, t, t+2}\left(s_{S, t, t}, a_{S, t, t}\right)$.

Given the optimal solutions for their middle-aged and old selves, the young sophisticates' problem (YSP) is solved; that is,

$$
\begin{aligned}
& \max _{c_{S, t, t}, S_{S, t, t}, a_{S, t, t}} \ln c_{S, t, t}+\beta \sum_{i=1}^{2} \delta^{i} \ln c_{S, t, t+i}\left(s_{S, t, t}, a_{S, t, t}\right) \\
& \text { s.t. } c_{S, t, t}+s_{S, t, t}+p_{t} a_{S, t, t} \leq w \\
& 0 \leq a_{S, t, t} \leq A,
\end{aligned}
$$

where (6) and (7) represent the budget and short-sale constraints, respectively. 


\subsection{Naïfs' problem}

In contrast, naïfs in each period determine their current behavior by maximizing their utility from the viewpoint of their current selves. As preference reversal takes place from period to period, naïfs revise the consumption plans made in previous periods.

Naive young consumers in period $t$ solve their following problem (YNP) to determine their current consumption and saving,

$$
\begin{aligned}
\max _{c_{N, t, t}, s_{N, t, t}, a_{N, t, t}, c_{N, t, t+1}^{t, t}, c_{N, t, t+2}, s_{N, t, t+1}^{t, t}, a_{N, t, t+1}^{t, t}} & \ln c_{N, t, t}+\beta \sum_{i=1}^{2} \delta^{i} \ln c_{N, t, t+i}^{t, t} \\
\text { s.t. } \quad c_{N, t, t}+s_{N, t, t}+p_{t} a_{N, t, t} & \leq w, \\
c_{N, t, t+1}^{t, t}+s_{N, t, t+1}^{t, t}+p_{t+1}^{t, t} a_{t, t+1}^{t, t} & \leq R_{t} s_{N, t, t}+p_{t+1}^{t, t} a_{N, t, t}, \\
c_{N, t, t+2}^{t, t} & \leq R_{t+1}^{t, t} s_{N, t, t+1}^{t, t}+p_{t+2}^{t, t} a_{N, t, t+1}^{t, t}, \\
0 & \leq a_{t, t} \leq A, \\
0 & \leq a_{N, t, t+1}^{t, t} \leq A,
\end{aligned}
$$

where $X^{t, t+i}$ is the anticipated value of $X$, which generation- $t$ naifs hold in period $t+i$, as indicated by the superscripts after $X$. The time $t+i$ consumption of naïfs in generation $t$ is represented by $c_{N, t, t+i}$, etc.

Equations (9) and (12) are the young naïfs' flow budget and short-sale constraints, respectively. Equations (10) and (13) represent the anticipated flow budget and short-sale constraints that the young naifs expect their middle-aged to face in the future; and (11) represents anticipated flow budget constraints that they expect their old selves. I emphasize that the constraints are anticipated because the naifs' future behavior and future market prices will deviate from their previous anticipations due to mis-anticipation of future preferences. 
Given the previous savings, the following middle-aged naïfs' problem (MNP) is resolved in period $t+1$ :

$$
\max _{c_{N, t, t+1}, s_{N, t, t+1}, a_{N, t, t+1}, c_{N, t, t+2}^{t, t+1}} \ln c_{N, t, t+1}+\beta \delta \ln c_{N, t, t+2}^{t, t+1}
$$

s.t. $\quad c_{N, t, t+1}+s_{N, t, t+1}+p_{t+1} a_{N, t, t+1} \leq R_{t} s_{t, t}+p_{t+1} a_{N, t, t}$,

$$
\begin{aligned}
& c_{N, t, t+2}^{t, t+1} \leq R_{t+1} s_{N, t, t+1}+p_{t+2}^{t, t+1} a_{N, t, t+1}, \\
& 0 \leq a_{N, t, t+1} \leq A, \\
& s_{N, t, t}, a_{N, t, t} \text { given, }
\end{aligned}
$$

where (15) and (16) are the flow budget constraints for middle-aged naïfs and for old naïfs, respectively. Equation (17) is the middle-aged naïfs' short-sale constraint.

I specify the expectations of naïs by the following two assumptions.

Assumption 2. Young naifs form expectations based on the belief that all consumers are naifs:

$$
c_{S, t, t+1}^{t, t}=c_{N, t, t+1}^{t, t}, c_{S, t+1, t+1}^{t, t}=c_{N, t+1, t+1}^{t, t}=c_{N, t, t}, \quad \forall t \in\{0,1,2, \ldots\}
$$

Assumption 3. Middle-aged and old naifs have perfect foresight:

$$
c_{N, t, t+2}^{t, t+1}=c_{N, t, t+2}, p_{t+2}^{t, t+1}=p_{t+2}, \quad \forall t \in\{0,1,2, \ldots\} .
$$

By Assumption 2, naïs are assumed to form expectations consistent with the model based on the misperception that the others consumers are naive, too. ${ }^{4} \mathrm{Be}$ cause of the misperception, young naïfs overestimate their future propensity to save

\footnotetext{
${ }^{4}$ Gabrieli (2011) proves that there is no competitive equilibrium in an economy inhabited by naïfs who have perfect foresight. Naïfs' expectations in this model correspond to the concept of a temporary competitive equilibrium in Gabrieli (2011).
} 
and hence future equilibrium asset prices. In contrast, by Assumption 1, sophisticated consumers correctly anticipate future asset prices. It follows that, as I will show later, young naïfs hold all assets in equilibrium.

By Assumption 3, naïfs are assumed to become sophisticated when middleaged, and be able to recognize which young consumers are naïve. In this simplified setting, only the young generation includes naïfs, who mis-forecast the future. Finding that newly born young naïfs overestimate future asset returns, middle-aged consumers who were naïve in the previous period but now have perfect foresight as sophisticates sell all their assets to young naiffs. Under Assumptions 2 and 3, assets are traded in this way between young naïfs and middle-aged former naïfs.

\subsection{Market equilibrium}

Market clearing conditions for loans and assets are described as follows:

$$
\begin{aligned}
& \frac{1}{1+m}\left(s_{N, t, t}+s_{N, t-1, t}\right)+\frac{m}{1+m}\left(s_{S, t, t}+s_{S, t-1, t}\right)=0, \\
& \frac{1}{1+m}\left(a_{N, t, t}+a_{N, t-1, t}\right)+\frac{m}{1+m}\left(a_{S, t, t}+a_{S, t-1, t}\right)=A,
\end{aligned}
$$

where, by Walras' law, the goods market clears when the market equilibrium conditions for loans and assets, (20) and (21), are met.

All consumers' expectations are rational in that they are model-consistent. The expectations of especially young naïfs' should satisfy the conditions

$$
\begin{gathered}
\frac{1}{1+m}\left(s_{N, t+1, t+1}^{t, t}+s_{N, t, t+1}^{t, t}\right)+\frac{m}{1+m}\left(s_{S, t+1, t+1}^{t, t}+s_{S, t, t+1}^{t, t}\right)=0, \\
\frac{1}{1+m}\left(a_{N, t+1, t+1}^{t, t}+a_{N, t, t+1}^{t, t}\right)+\frac{m}{1+m}\left(a_{S, t+1, t+1}^{t, t}+a_{S, t, t+1}^{t, t}\right)=A .
\end{gathered}
$$

Note that, irrespective of model consistency, young naïfs' expectations are biased 
due to their misperception (18).

The competitive equilibrium is a sequence of interest rates and the asset prices $\left\{p_{t}, R_{t}\right\}$ such that sophisticates first solve the MSP and then the YSP backwardly; young naïs solve their problem (YNP) and middle-aged naïfs theirs (YMP); the markets for goods, assets, and loans clear; and young naïfs' expectations satisfy (22) and (23). The initial condition of the economy is given by the amounts of asset holding and lending by generations -1 and $-2\left(a_{j,-2,-1}, s_{j,-2,-1}, a_{j,-1,-1}, s_{j,-1,-1}\right)$, $j=N, S$.

\section{No-bankruptcy equilibrium}

I first focus on the no-bankruptcy equilibrium, in which no naïfs fall into bankruptcy. Let me start with the assumption that no consumers fall into bankruptcy. Later, I will show a necessary and sufficient condition parametrically for this assumption to hold valid.

To characterize the equilibrium of the model, I guess that, in equilibrium, young

naifs' expected asset price for the next period, $p_{t+1}^{t, t}$, is higher than the actual asset price for the same period, $p_{t+1}$, because they incorrectly overestimate aggregate saving. From the first-order condition, the resulting expected returns on the asset, $p_{t+1}^{t, t} / p_{t}$, should in turn equal the interest rate, $R_{t}$. These relations are summarized as

$$
R_{t}=\frac{p_{t+1}^{t, t}}{p_{t}}>\frac{p_{t+1}}{p_{t}}, \quad \forall t \in\{0,1,2, \ldots\}
$$

With the return structure, sophisticates do not hold any asset, while middle-aged 
naïfs sell and young naïfs buy all assets. That is,

$$
a_{S, t, t}=a_{S, t-1, t}=a_{N, t-1, t}=0, a_{N, t, t}=A(1+m), \quad \forall t \in\{0,1,2, \ldots\} .
$$

Note that this condition does not contradict each player's optimality. For sophisticates, the return inequality (24) does not violate their arbitrage condition because they hold no asset and cannot sell short.

Note that although young naifs can observe that the amount of sophisticates' asset holdings differ from that of young naîfs', this fact does not contradict Assumption 2 , because holding assets is indifferent to lending. ${ }^{5}$ Moreover, I assume that each young naif holds the same amount of the asset, $(1+m) A$.

\section{Insert Figure 1.}

Figure 1 illustrates how a consumer exchanges the asset and contracts loans in an equilibrium. Young naïfs buy all the assets $A$ by paying $p_{t} A$ units of consumption goods and borrowing $s_{S, t-1, t}, s_{S, t, t}$, and $s_{N, t-1, t}$ from middle-aged sophisticates, young sophisticates, and middle-aged naïfs, respectively. Middle-aged naïfs sell all assets to realize actual returns $p_{t+1} / p_{t}$ and repay all loans paying interest rate $R_{t}$. However, these transactions may bankrupt them since the interest rate is higher than the actual asset returns.

Under the equilibrium returns (24) and asset holdings (25) structures, the optimal behavior of each consumer can be obtained as follows. From the YSP, MSP, and YNP, sophisticates' consumption behavior and young naïfs' optimal consump-

\footnotetext{
${ }^{5}$ The no-arbitrage condition ensures that $R_{t+1}^{t, t}=p_{t+2}^{t, t} / p_{t+1}^{t, t}, \forall t \in\{0,1,2, \ldots\}$.
} 
tion plan must satisfy

$$
\begin{aligned}
c_{S, t, t} & =c_{N, t, t}=\frac{w}{1+\beta \delta+\beta \delta^{2}}, \\
c_{S, t, t+1} & =\frac{1+\delta}{1+\beta \delta} \frac{\beta \delta R_{t} w}{1+\beta \delta+\beta \delta^{2}}, \\
c_{S, t, t+2} & =\frac{\beta(1+\delta)}{1+\beta \delta} \frac{\beta \delta^{2} R_{t} R_{t+1} w}{1+\beta \delta+\beta \delta^{2}}, \\
c_{N, t, t+1}^{t, t} & =\frac{\beta \delta R_{t} w}{1+\beta \delta+\beta \delta^{2}}, \\
c_{N, t, t+2}^{t, t} & =\frac{\beta \delta^{2} R_{t} R_{t+1}^{t, t} w}{1+\beta \delta+\beta \delta^{2}} .
\end{aligned}
$$

Irrespective of the young naifs' overconfidence about their future patience, (26) reveals, from the property of the logarithmic utility function, that the optimal consumption of time- $t$ young naïfs, $c_{N, t, t}$, equals the young sophisticates' consumption $c_{S, t, t}$ at time $t$. From (27) and (29), young naïfs plan to consume less when middleaged than middle-aged sophisticates consume. However, from (28) and (30), young naïs do not necessarily plan to enjoy greater consumption when old than old sophisticates do because they mis-forecast that the expected interest is lower than the actual, $R_{t+1}^{t, t}<R_{t+1}$. From the property of naifs, this future consumption plan of young naïfs will not be realized in either case. Far from it-their consumption rates, when they are middle-aged and old, are lower than those of sophisticates, as is shown below.

Middle-aged naifs experience a lower asset price than they expected when young and suffer capital losses when repaying their debt by selling assets. To show this formally, substitute (9) and (24)-(26) into (15) and (16) to rewrite the budget con- 
straint of middle-aged naïfs as

$$
\begin{aligned}
c_{N, t, t+1}+s_{N, t, t+1} & \leq \frac{\beta \delta(1+\delta) w R_{t}}{1+\beta \delta+\beta \delta^{2}}-p_{t+1}(1+m) A\left(\frac{p_{t+1}^{t, t}}{p_{t+1}}-1\right), \\
c_{N, t, t+2} & \leq R_{t+1} s_{N, t, t+1}
\end{aligned}
$$

where the right-hand side of (31) represents the net wealth of middle-aged naifs. The second term, $p_{t+1} A(1+m)\left(\left(p_{t+1}^{t, t} / p_{t+1}\right)-1\right)$, represents the capital loss that middle-aged naïs suffer, which is proportionate to the nominal interest rate $\left(p_{t+1}^{t, t} / p_{t+1}\right)-1 .^{6}$ Note that, without the naïfs' misperception about the future saving propensity, the nominal interest rate, and hence the capital loss for middleaged naïfs, would be zero, as in the standard overlapping generations model (e.g., Samuelson, 1958; Tirole, 1985).

By incorporating constraints (31) and (32), middle-aged naïs solve their problem (MNP) to obtain

$$
\begin{aligned}
& c_{N, t, t+1}=c_{S, t, t+1}-\frac{1}{1+\beta \delta} p_{t+1} A(1+m)\left(\frac{p_{t+1}^{t, t}}{p_{t+1}}-1\right)<c_{S, t, t+1}, \\
& c_{N, t, t+1}=c_{S, t, t+2}-\frac{\beta \delta R_{t+1}}{1+\beta \delta} p_{t+1} A(1+m)\left(\frac{p_{t+1}^{t, t}}{p_{t+1}}-1\right)<c_{S, t, t+2} .
\end{aligned}
$$

These solutions reveal that, unlike the previously planned consumption functions (29) and (30), not only middle-aged naïs but also old naïfs consume less than contemporary sophisticates. This takes place due to the unexpected capital loss.

The expected and actual borrowing/lending behavior of the young and the middleaged $\left(s_{N, t+1, t+1}^{t, t}, s_{S, t+1, t+1}^{t, t}, s_{N, t, t+1}^{t, t}, s_{S, t, t+1}^{t, t}, s_{N, t, t}, s_{S, t, t}, s_{N, t-1, t}\right.$ and $\left.s_{S, t-1, t}\right)$ is obtained

\footnotetext{
${ }^{6}$ When asset $A$ represents money, the gross rate of inflation equals $p_{t} / p_{t+1}$. The gross nominal interest rate is obtained as the real interest rate, $R_{t}=p_{t+1}^{t, t} / p_{t}$, times the inflation rate $p_{t} / p_{t+1}$, which equals $p_{t+1}^{t, t} / p_{t+1}$.
} 
by substituting their optimal consumption and asset holdings into the corresponding budget constraints (see Appendix A). Under Assumption 2, the naifs' expectations about the asset price are obtained by substituting the expected borrowing/lending behavior and asset holdings of each consumer into (22) and (23) as

$$
p_{t+1}^{t, t}=\frac{\beta \delta(1+\delta) w p_{t}}{\left(1+\beta \delta+\beta \delta^{2}\right) A p_{t}-\beta \delta^{2} w} .
$$

The equilibrium solution is obtained by successively substituting the actual borrowing/lending behavior and price expectations (35) into the market equilibrium conditions (20) as

$$
p_{t}=\frac{\beta \delta(1+\delta) w\left(\left(1+\beta \delta+\beta \delta^{2}\right) A p_{t-1}-\beta \delta^{2} w(1-\beta)\right)}{\left(1+\beta \delta+\beta \delta^{2}\right) A\left(\left(1+\beta \delta+\beta \delta^{2}\right) A p_{t-1}-\beta \delta^{2} w\right)}
$$

The interest rate is obtained by dividing (35) by $p_{t}$ as

$$
R_{t}=\frac{\beta \delta(1+\delta) w}{\left(1+\beta \delta+\beta \delta^{2}\right) A p_{t}-\beta \delta^{2} w} .
$$

The following lemma ensures that the asset price and gross interest rate in equilibrium are positive.

Lemma 1. If no generation falls into bankruptcy, the asset price satisfies

$$
p_{t}>\frac{\beta \delta(1+\delta) w}{\left(1+\beta \delta+\beta \delta^{2}\right) A}
$$

for all $t$.

Proof. See Appendix B.

Insert Figure 2. 
By setting $p_{t}=p_{t-1}$ in (36) and solving the resulting quadratic equation, I obtain two possible solutions for the steady-state equilibrium price, as depicted by points $\mathrm{E}$ and NE in Figure 2. However, I can verify that the lower price solution (point NE) is not supported by equilibrium (see Appendix C). This implies that the steady-state no-bankruptcy equilibrium is unique. I thus focus on the higher price solution (E) as the equilibrium price from now on.

Recall that the equilibrium solution is obtained by guessing that the young naifs' expected asset price is higher than the actual price for the same period, as in (24), and, therefore, that sophisticates do not hold any asset, middle-aged naïfs sell all assets, and young naïfs buy all assets, as in (25). To check the validity of this assumption, I take the difference between (35) and (36) to obtain

$$
p_{t+1}^{t, t}-p_{t+1}=\frac{\beta^{2} \delta^{3}(1+\delta) w^{2}(1-\beta)}{A\left(1+\beta \delta+\beta \delta^{2}\right)\left(\left(1+\beta \delta+\beta \delta^{2}\right) A p_{t}-\beta \delta^{2} w\right)}
$$

From Lemma 1, this is indeed positive in equilibrium.

Letting $p, p^{f}$, and $R$ denote the steady-state values of $p_{t}, p_{t+1}^{t, t}$, and $R_{t}$, the steady-state equilibrium solution, which corresponds to point E in Figure 2, can be obtained from (35), (36), and (37) as

$$
\begin{aligned}
p & =\frac{\beta \delta w}{2\left(1+\beta \delta+\beta \delta^{2}\right) A}(1+2 \delta+\sqrt{1+4 \beta \delta(1+\delta)}) \\
p^{f} & =\frac{\beta \delta(1+\delta) w(1+2 \delta+\sqrt{1+4 \beta \delta(1+\delta)})}{\left(1+\beta \delta+\beta \delta^{2}\right) A(1+\sqrt{1+4 \beta \delta(1+\delta)})} \\
R & =\frac{2(1+\delta)}{1+\sqrt{1+4 \beta \delta(1+\delta)}}>1
\end{aligned}
$$

As pointed out previously, the steady-state gross interest rate is larger than one, unlike in the standard overlapping generations model, in which the nominal interest 
rate is zero.

The time- $t$ equilibrium price is obtained by solving the autonomous nonlinear difference equation (36). The detailed derivation is provided in Appendix C. For a given initial price $p_{0}$, it can be solved analytically and expressed in terms of the steady-state value $p$ as

$$
p_{t}=\frac{(1+\alpha)\left(p_{0}-p\right)}{(-1)^{t} \alpha^{t}\left(1+\alpha+\gamma\left(p_{0}-p\right)\right)-\gamma\left(p_{0}-p\right)}+p
$$

where

$$
\begin{aligned}
& \alpha=1+\frac{1+2 \sqrt{1+4 \beta \delta(1+\delta)}}{2 \beta \delta(1+\delta)}, \\
& \gamma=\frac{2\left(1+\beta \delta+\beta \delta^{2}\right) A}{\beta \delta w(\sqrt{1+4 \beta \delta(1+\delta)}-1)} .
\end{aligned}
$$

Equation (42) implies that the steady-state solution $p$ is globally stable because $\alpha>1$, so that $p_{t}$ converges toward $p$ over time for any initial value satisfying the assumption that no consumers fall into bankruptcy.

I now consider the assumption that no consumers fall into bankruptcy. The necessary and sufficient condition under which middle-aged naïfs do not fall into bankruptcy is given by the following lemma.

Lemma 2. In an equilibrium, no generation falls into bankruptcy if and only if

$$
a_{j,-1,-1}>-\frac{\left(1+\beta \delta+\beta \delta^{2}\right) A}{\beta \delta(1+\delta) w} s_{j,-1,-1}, \quad j=N, S
$$

and

$$
\frac{1+\beta \delta}{\delta(1-\beta)}>m
$$


Proof. See Appendix D.

Equation (43) implies that middle-aged naifs in the initial generation have positive wealth; (44) implies that middle-aged naifs have strictly positive wealth for $t=$ $1,2, \ldots$

From this lemma, middle-aged naïs are likely to fall into bankruptcy (i) when the degree of present bias, $1 / \beta$, is high (ii) when the sophisticate-naïf population ratio $m$ is high, and (iii) when the long-run discount factor $\delta$ is high. Intuitively, with a lower $\beta$, young naïfs overestimate future asset prices to a greater extent, and suffer greater loss when they are middle-aged. A higher $m$ implies a greater amount of sophisticates' arbitrage transactions and hence a higher possibility of bankruptcy for the middle-aged.

The property that a higher $\delta$ is associated with a higher probability of bankruptcy-i.e., (iii) above-is rather counter-intuitive because a higher $\delta$ implies a higher saving rate. This takes place because, with a given beta, a higher delta magnifies misperception of future discount factors, $\delta(1-\beta)$, and hence leads to greater future loss.

Recall that the no-bankruptcy equilibrium, which is consistent with the initial guess (24), is unique (see Figure 2). I can also show that a no-bankruptcy equilibrium that contradicts (24) does not exist (see Appendix E). Therefore, a nobankruptcy equilibrium uniquely exists under conditions (43) and (44). The above results regarding equilibrium dynamics are summarized as follows

Proposition 1. If $a_{j,-1,-1}>-\left(1+\beta \delta+\beta \delta^{2}\right) A s_{j,-1,-1} / \beta \delta(1+\delta) w(j=N, S)$ and $(1+\beta \delta) / \delta(1-\beta)>m$ is satisfied,

(i) a no-bankruptcy equilibrium uniquely exists,

(ii) the steady-state solution $p$ is globally stable. 


\section{Bankruptcy equilibrium}

Let me next consider the case

$$
\frac{1+\beta \delta}{\delta(1-\beta)} \leq m
$$

in which, from Lemma 2, middle-aged naïfs fall into bankruptcy. I also specify the initial conditions for $\left(a_{S,-1,0}, s_{S,-1,0}\right)$ to exclude the trivial case in which sophisticates in the initial generation do not fall into bankruptcy. To close the model, I specify a debt adjustment method such that each sophisticate gets the amount $-p_{t+1} a_{N, t, t} s_{S, k, t} / s_{N, t, t}(k=t-1, t)$ from naïfs' liquidated asset $p_{t+1} a_{N, t, t}$ in proportion to his credit share $-s_{k, t} / s_{N, t, t}{ }^{7}$

Since young naïs do not know that they will fall into bankruptcy in the next period, their behavior in this case is the same as described in (26) and (35) in Section 3. In contrast, sophisticates know that young naïfs will fall into bankruptcy. Regardless, sophisticates still have an incentive to lend to young naïfs if an effective interest rate, which is computed from the amounts paid back from bankrupts, is higher than the rate of asset return. The effective interest rate for sophisticates is given by

$$
\rho_{t} \equiv-\frac{p_{t+1} a_{N, t, t}}{s_{N t, t}}
$$

From the discussions, sophisticates' budget constraints (2) and (3) are rewritten

\footnotetext{
${ }^{7}$ One such repayment system is a creditor meeting.
} 


$$
\begin{aligned}
c_{S, t, t+1}+s_{S, t, t+1}+p_{t+1} a_{S, t, t+1} & \leq \rho_{t} s_{S, t, t}+p_{t+1} a_{S, t, t}, \\
c_{S, t, t+2} & \leq \rho_{t+1} s_{S, t, t+1}+p_{t+2} a_{S, t, t+1},
\end{aligned}
$$

where $\rho_{t}$ and $\rho_{t+1}$ are given to sophisticates. The first terms on the right-hand sides of (47) and (48) represent the repayments from the bankrupts. Each middle-aged sophisticate maximizes (1) subject to the budget constraints (47) and (48) and the short-sale constraint (4). The young sophisticates solve their YSP in turn, given the resulting optimal behavior of their middle-aged and old selves.

As can easily be conjectured from the discussion in Section 3, an equilibrium is characterized by the same equilibrium return and asset holding structures as (24) and (25). Under these structures, I get the sophisticates' optimal consumption by replacing $R$ with $\rho$ in (26)-(28) as

$$
\begin{aligned}
c_{S, t, t} & =\frac{w}{1+\beta \delta+\beta \delta^{2}} \\
c_{S, t, t+1} & =\frac{1+\delta}{1+\beta \delta} \frac{\beta \delta w \rho_{t}}{1+\beta \delta+\beta \delta^{2}}, \\
c_{S, t, t+2} & =\frac{\beta(1+\delta)}{1+\beta \delta} \frac{\beta \delta^{2} \rho_{t} \rho_{t+1}}{1+\beta \delta+\beta \delta^{2}} .
\end{aligned}
$$

The equilibrium effective interest rate can be obtained by substituting (9), (25), and (26) into (46) as

$$
\rho_{t}=\frac{\left(1+\beta \delta+\beta \delta^{2}\right) p_{t+1}(1+m) A}{\left(1+\beta \delta+\beta \delta^{2}\right) p_{t}(1+m) A-\beta \delta(1+\delta) w}>\frac{p_{t+1}}{p_{t}}
$$

This implies that the effective gross interest rate is indeed higher than the asset return. Note that when $m \rightarrow \infty, \rho_{t} \rightarrow p_{t+1} / p_{t}$. That is, as the population share of 
sophisticates approaches one, the returns on lending and asset holding are equalized as in the equilibrium of the economy inhabited only by sophisticates.

As shown in Appendix F, I can derive the equilibrium solution by noting $\left(c_{N, t-1, t}, a_{N, t-1, t}, s_{N, t-1, t}\right)=0$, and substituting (49)-(52) and the other optimal solutions into the market equilibrium conditions (20) as follows:

$$
p_{t}=\frac{\theta\left((1+m)\left(1+\beta \delta+\beta \delta^{2}\right) A p_{t-1}-\beta \delta(1+\delta) w\right)}{(1+m)(1+\beta \delta)\left(1+\beta \delta+\beta \delta^{2}\right) A p_{t-1}-(1+(1+m) \beta \delta) \beta \delta(1+\delta) w}
$$

where $\theta=\beta \delta(1+\beta \delta)(1+\delta) w /\left(\left(1+\beta \delta+\beta \delta^{2}\right) A\right)$. The following lemma ensures that (53) is positive.

Lemma 3. In bankruptcy equilibrium, if sophisticates in the initial generations do not fall into bankruptcy, solution (53) satisfies

$$
p_{t}>\frac{\beta \delta(1+\delta) w}{\left(1+\beta \delta+\beta \delta^{2}\right) A}
$$

for all $t$.

Proof. See Appendix B.

Therefore, under the trivial condition that initial-generation sophisticates do not fall into bankruptcy, (45) ensures that solution (53) is positive and hence viable as an equilibrium price.

Taking the difference between (37) and (52) and substituting (53) into the result yield

$$
R_{t}-\rho_{t}=\frac{(\delta m(1-\beta)-(1+\beta \delta))\left(1+\beta \delta+\beta \delta^{2}\right) A R_{t} p_{t+1}}{\beta \delta(1+\beta \delta)(1+\delta)\left((1+m)\left(1+\beta \delta+\beta \delta^{2}\right) A p_{t}-\beta \delta(1+\delta) w\right)}
$$


From (45) and Lemma 3, this implies that $R_{t} \geq \rho_{t}$, where the equality holds if and only if the equality holds in (45). To sum up, the relationships among the gross interest rate, the effective gross interest rate, and the return of the asset are obtained from (52) and (54) as

$$
R_{t}=\frac{p_{t+1}^{t, t}}{p_{t}} \geq \rho_{t}>\frac{p_{t+1}}{p_{t}}
$$

which implies that the expected asset price is higher than the actual asset price and, hence, that (24) and (25) are indeed satisfied in this equilibrium.

\section{Insert Figure 3.}

By the same argument presented in Section 3, I can obtain a stable as well as an unstable solution for the steady-state asset price. The unstable solution is not supported by equilibrium. The stable steady-state solution is given by

$$
p=\frac{\beta \delta(1+\delta) w\left(2(1+m)(1+\beta \delta)-m+\sqrt{4 \beta \delta m(1+m)(1+\beta \delta)+m^{2}}\right)}{2(1+m)(1+\beta \delta)\left(1+\beta \delta+\beta \delta^{2}\right) A}
$$

As I did in Section 3, I can solve the autonomous nonlinear difference equation (53) and show the unique existence and stability of the resulting equilibrium. From Lemma 2, sophisticates in the initial generation do not fall into bankruptcy if and only if their asset positions $a_{S,-1,-1}$ and $s_{S,-1,-1}$ satisfy

$$
a_{S,-1,-1}>-\frac{\left(1+\beta \delta+\beta \delta^{2}\right) A}{\beta \delta(1+\delta) w} s_{S,-1,-1}
$$


and hence the initial equilibrium price satisfies

$$
p_{0}>\frac{\beta \delta(1+\delta) w}{\left(1+\beta \delta+\beta \delta^{2}\right) A} .
$$

For any initial asset price that satisfies this condition, the solution to (53) gives the unique equilibrium price that converges stably to the steady-state value (55). The following proposition summarizes the above results regarding bankruptcy equilibrium dynamics.

Proposition 2. If $a_{S,-1,-1}>-\left(1+\beta \delta+\beta \delta^{2}\right) A s_{S,-1,-1} / \beta \delta(1+\delta) w$ and $(1+\beta \delta) / \delta(1-\beta) \leq m$ are satisfied,

(i) a bankruptcy equilibrium uniquely exists, and

(ii) the steady-state solution $p$ is globally stable.

\section{Inefficiency in the steady state}

To examine the allocation efficiency of the steady-state equilibrium, I first define $c_{j, 1}, c_{j, 2}$, and $c_{j, 3}(j=N, S)$ as the steady-state consumption of the young, middleaged, and old, respectively. I need an ex-post efficiency criterion because naïfs experience unexpected capital losses, and hence ex-post welfare deterioration, when they are middle-aged. Since sophisticates' planned lifetime utility is realized, I focus on the young naïfs' ex-post, or experienced, lifetime utility

$$
U=\ln c_{N, t, t}+\beta \sum_{i=1}^{2} \delta^{i} \ln c_{N, t, t+i}
$$

where $c_{N, t, t}, c_{N, t, t+1}$ and $c_{N, t, t+2}$ denote actual consumption. The experienced lifetime utilities for old sophisticates and old naïs are $\ln c_{S, t-2, t}$ and $\ln c_{N, t-2, t}$, respec- 
tively; and the experienced lifetime utilities for young sophisticates, middle-aged sophisticates, and middle-aged naifs are the same form as (5), (1), and (14), respectively. Here, the ex-post Pareto-efficient allocation is defined as follows:

Definition 1 (ex-post Pareto efficiency). A resource allocation is ex-post Pareto efficient if and only if there is no feasible allocation improving someone's experienced utility without harming another's.

In my overlapping generations economy, the resource allocation of the steadystate equilibrium is ex-post Pareto inefficient. To show this, consider that a paternalistic planner forces young naifs to reduce $\Delta$ units of steady-state consumption, and thereby transfers $\Delta /(1+\delta)$ units from young to middle-aged naïfs, and $\delta \Delta /(1+\delta)$ units to old naïfs. For any $\Delta$, the welfare of middle-aged and old naïs is definitely enhanced.

Moreover, if $\Delta$ is small enough, young naifs suffer marginal disutility from reducing consumption, $-1 / c_{N, 1}$, and will enjoy time-discounted marginal utility from increasing consumption in the future, $(\beta \delta /(1+\delta))\left(1 / c_{N, 2}+\delta^{2} / c_{N, 3}\right)$. Note that sophisticates' consumption and lifetime utility do not change since naifs' saving does not change, and thereby market prices do not change. Thus, if the total marginal utility (TMU), $-1 / c_{N, 1}+(\beta \delta /(1+\delta))\left(1 / c_{N, 2}+\delta^{2} / c_{N, 3}\right)$, is positive, the allocation is ex-post Pareto inefficient. Indeed, in a bankruptcy economy, the TMU approaches positive infinity, and in a no-bankruptcy economy, because of (44), the TMU is always positive as follows:

$$
\mathrm{TMU}=\frac{\left(1+\beta \delta+\beta \delta^{2}\right)(1-\beta) \delta(2(1-\beta)(1+\beta \delta)+m \kappa)}{w(1+\beta \delta-m \delta(1-\beta)) \kappa}>0
$$

where $\kappa=(\delta+\beta+\beta \delta) \sqrt{1+4 \beta \delta(1+\delta)}+\delta+\beta(1+\delta)(1+4 \delta)$.

Proposition 3. The allocation of resources in a steady state is ex-post Pareto inef- 
ficient either in a no-bankruptcy economy or in a bankruptcy economy.

Intuitively, they consume too much when young and, hence, too little thereafter because of unexpected capital losses. Unexpected capital losses not only reduce middle-aged naïfs' wealth but also result in a divergence between young naifs' actual and optimal consumption.

\section{Conclusion}

I construct the model of a dynamic economy in which sophisticates exploit naifs through capital transactions. This paper shows three properties of the nobankruptcy/bankruptcy equilibrium in an economy: global dynamics and stability, a bankruptcy condition, and ex-post Pareto inefficiency. These properties except bankruptcy condition are largely preserved if the model is extended as follows: (i) the asset yields $d(>0)$ units consumption in every period, and (ii) consumers must consume at least $c(>0)$. The first extension does not affect the bankruptcy condition, whereas the second extension changes the condition to one depending on the asset price. Thus, in the economy with the positive lower bound of the consumption, an equilibrium moves back and forth between a no-bankruptcy equilibrium and a bankruptcy equilibrium if the asset price oscillates widely.

It would be worth introducing partial naifs, who recognize present bias but not its degree, into this model from O'Donoghue and Rabin (2001). According to Wong (2008), partial naïfs account for almost fifty percent of all samples, so this device would be plausible. This device could be utilized to separate the degree of misperception from the degree of present bias and to relax Assumptions 2 and 3. Therefore, introducing partial naïfs into this model would be helpful to analyze a variety of misperceptions and understand present bias. 
Finally, the potential applications of bankruptcy equilibriums abound since a change in the debt adjustment method means a change in the bankruptcy equilibrium. For example, a borrowing constraint is introduced into this model from Kiyotaki and Moore (1997).

\section{Appendix A Borrowing/lending behavior}

Under Assumption 2, the expected borrowing/lending behavior of the young and the middle-aged is obtained by computing YNP. By substituting young naïfs' optimal consumption (26) and (30) into budget constraint (9) and (11), respectively, I have

$$
\begin{aligned}
s_{N, t+1, t+1}^{t, t}+p_{t+1}^{t, t} a_{N, t+1, t+1}^{t, t} & =\frac{\beta \delta(1+\delta) w}{1+\beta \delta+\beta \delta^{2}}, \\
s_{S, t+1, t+1}^{t, t}+p_{t+1}^{t, t} a_{S, t+1, t+1}^{t, t} & =\frac{\beta \delta(1+\delta) w}{1+\beta \delta+\beta \delta^{2}}, \\
s_{N, t, t+1}^{t, t}+p_{t+1}^{t, t} a_{N, t, t+1}^{t, t} & =\frac{\beta \delta^{2} w R_{t}}{1+\beta \delta+\beta \delta^{2}}, \\
s_{S, t, t+1}^{t, t}+p_{t+1}^{t, t} a_{S, t, t+1}^{t, t} & =\frac{\beta \delta^{2} w R_{t}}{1+\beta \delta+\beta \delta^{2}},
\end{aligned}
$$

where (A.1) is the generation- $t$ young naïfs' borrowing/lending behavior and (A.3) is the borrowing/lending behavior of the expected generation- $t$ middle-aged naifs. Note that (A.2) and (A.4) are similar in form to (A.1) and (A.3), respectively, since $c_{S, i, i+1}^{i, i}=c_{N, i, i+1}^{i, i}, c_{S, i+1, i+1}^{i, i}=c_{N, i+1, i+1}^{i, i}$ by Assumption 2.

By successively substituting (25) and (26) into both (6) and (9), I have

$$
\begin{aligned}
s_{N, t, t}+p_{t} A(1+m) & =\frac{\beta \delta(1+\delta) w}{1+\beta \delta+\beta \delta^{2}} \\
s_{S, t, t} & =\frac{\beta \delta(1+\delta) w}{1+\beta \delta+\beta \delta^{2}}
\end{aligned}
$$


respectively. Moreover, by successively substituting (25) and (28) into (3), I have

$$
s_{N, t, t+1}=\frac{\beta \delta}{1+\beta \delta}\left(\frac{\beta \delta(1+\delta) w R_{t}}{1+\beta \delta+\beta \delta^{2}}-A(1+m)\left(p_{t+1}^{t, t}-p_{t+1}\right)\right) .
$$

Similarly, by successively substituting (25) and (34) into (16), I also have

$$
s_{S, t, t+1}=\frac{\beta(1+\delta)}{1+\beta \delta} \frac{\beta \delta^{2} w R_{t}}{1+\beta \delta+\beta \delta^{2}} .
$$

\section{Appendix B Proofs of Lemma 1 and Lemma 3}

At time 0 , the initial generations, -1 and 0 , consume

$$
\begin{aligned}
c_{j,-1,0} & =\frac{1}{1+\beta \delta}\left(s_{j,-1,-1}+p_{0} a_{j,-1,-1}\right), \quad j=N, S, \\
c_{j, 0,0} & =\frac{w}{1+\beta \delta+\beta \delta^{2}}, \quad j=N, S,
\end{aligned}
$$

respectively. By substituting (B.1) and (B.2) into each budget constraint, I obtain the borrowing/lending behavior of initial generations. The equilibrium solution is obtained by substituting the borrowing/lending behavior into the market equilibrium conditions (20) as

$$
p_{0}=\frac{\beta \delta(1+\delta) w}{\left(1+\beta \delta+\beta \delta^{2}\right) A}+\frac{\beta \delta\left(s_{j,-1,-1}+p_{0} a_{j,-1,-1}\right)}{(1+\beta \delta) A} .
$$

On the other hand, if generation -1 does not fall into bankruptcy, the following inequality holds:

$$
s_{j,-1,-1}+p_{0} a_{j,-1,-1}>0, \quad j=N, S .
$$


Using inequality (B.4), I can obtain the lower bound of the initial asset price

$$
p_{0}>\frac{\beta \delta(1+\delta) w}{\left(1+\beta \delta+\beta \delta^{2}\right) A} .
$$

I now need to consider the asset price at time $t$. I rewrite the asset price (36) as

$$
p_{t}=\frac{\frac{\beta^{3} \delta^{3}(1+\delta) w^{2}}{\left(1+\beta \delta+\beta \delta^{2}\right)^{2} A^{2}}}{p_{t-1}-\frac{\beta \delta^{2} w}{\left(1+\beta \delta+\beta \delta^{2}\right) A}}+\frac{\beta \delta(1+\delta) w}{A\left(1+\beta \delta+\beta \delta^{2}\right)} .
$$

Using (B.5) and (B.6), I can prove Lemma 1 by mathematical induction.

Next, I consider the case where middle-aged naïfs are bankrupts. Here, $s_{N,-1,0}=$ 0 , and the remainder is the same as above. With $s_{N,-1,0}=0$, I have a minor change in the equilibrium solution as follows:

$$
p_{0}=\frac{\beta \delta(1+\delta) w}{\left(1+\beta \delta+\beta \delta^{2}\right) A}+\frac{m \beta \delta\left(s_{S,-1,-1}+p_{0} a_{S,-1,-1}\right)}{(1+m)(1+\beta \delta) A}
$$

Since the initial generation -1 of sophisticates does not fall into bankruptcy, $s_{S,-1,-1}+$ $p_{0} a_{S,-1,-1}>0$ holds. Using this inequality, the lower bound of the initial asset price is given in a form similar to that of (B.5). Since I can rewrite the asset price (53) as

$$
p_{t}=\frac{\frac{\beta^{3} \delta^{3}(1+\delta)^{2} w^{2} m}{(1+\beta \delta)(1+m)\left(1+\beta \delta+\beta \delta^{2}\right)^{2} A^{2}}}{p_{t-1}-\frac{(1+(1+m) \beta \delta) \beta \delta(1+\delta) w}{(1+m)(1+\beta \delta)\left(1+\beta \delta+\beta \delta^{2}\right) A}}+\frac{\beta \delta(1+\delta) w}{\left(1+\beta \delta+\beta \delta^{2}\right) A}
$$

Lemma 3 is proved by mathematical induction. 


\section{Appendix C Detailed derivation of nonlinear equation (36)}

By setting $p_{t}=p_{t-1}=p$ in (36), I obtain the quadratic equation

$$
\frac{\left(1+\beta \delta+\beta \delta^{2}\right) A}{\beta \delta w} p^{2}-(1+2 \delta) p+\frac{\beta \delta^{2}(1+\delta) w(1-\beta)}{\left(1+\beta \delta+\beta \delta^{2}\right) A}=0 .
$$

This equation has two solutions. One of these solutions is (39), and the other is given by

$$
p^{-}=\frac{\beta \delta w}{2\left(1+\beta \delta+\beta \delta^{2}\right) A}(1+2 \delta-\sqrt{1+4 \beta \delta(1+\delta)}) .
$$

This solution is not supported by equilibrium since (C.1) is lower than the lower bound of the asset price; i.e., $\beta \delta(1+\delta) w /\left(1+\beta \delta+\beta \delta^{2}\right) A>p^{-}$. Thus, I focus on the solution of the nonlinear equation by using the steady-state solution (39).

The system of nonlinear equation is given by

$$
\begin{aligned}
& \beta \delta^{2} w p_{t}+\beta \delta(1+\delta) w p_{t-1} \\
& =\left(1+\beta \delta+\beta \delta^{2}\right) A p_{t} p_{t-1}+\frac{\beta^{2} \delta^{3}(1+\delta)(1-\beta) w^{2}}{\left(1+\beta \delta+\beta \delta^{2}\right) A}
\end{aligned}
$$

I first add $-p+p$ to $p_{t}$ as follows:

$$
\begin{aligned}
& \beta \delta^{2} w\left(p_{t}-p+p\right)+\beta \delta(1+\delta) w\left(p_{t-1}-p+p\right) \\
& =\left(1+\beta \delta+\beta \delta^{2}\right) A\left(p_{t}-p+p\right)\left(p_{t-1}-p+p\right)+\frac{\beta^{2} \delta^{3}(1+\delta)(1-\beta) w^{2}}{\left(1+\beta \delta+\beta \delta^{2}\right) A}
\end{aligned}
$$


Using (C.2), I compute (C.3) to make teams, $1 /\left(p_{k}-p\right)(k=t-1, t)$, as follows:

$$
\begin{aligned}
& \frac{\left(\left(1+\beta \delta+\beta \delta^{2}\right) A p-\beta \delta^{2} w\right)}{\left(p_{t-1}-p\right)}+\frac{\left(\left(1+\beta \delta+\beta \delta^{2}\right) A p-\beta \delta(1+\delta) w\right)}{\left(p_{t}-p\right)} \\
& =\left(1+\beta \delta+\beta \delta^{2}\right) A .
\end{aligned}
$$

Letting $x_{t} \equiv 1 /\left(p_{t}-p\right)$, I can express (C.4) as a system of linear first-order difference equations:

$$
x_{t}=-\alpha x_{t-1}-\gamma
$$

where

$$
\begin{aligned}
\alpha & =\frac{\left(1+\beta \delta+\beta \delta^{2}\right) A p+\beta \delta^{2} w}{\left(1+\beta \delta+\beta \delta^{2}\right) A p-\beta \delta(1+\delta) w} \\
\gamma & =\frac{\left(1+\beta \delta+\beta \delta^{2}\right) A}{\left(1+\beta \delta+\beta \delta^{2}\right) A p-\beta \delta(1+\delta) w}
\end{aligned}
$$

Then, since the system of linear first-order difference equations can be solved, I have

$$
p_{t}=\frac{(1+\alpha)\left(p_{0}-p\right)}{(-1)^{t} \alpha^{t}\left(1+\alpha+\gamma\left(p_{0}-p\right)\right)-\gamma\left(p_{0}-p\right)}+p
$$

\section{Appendix D Proof of Lemma 2}

Condition (43) is obtained from (B.4) and (B.5). In turn, I consider condition (44). By successively substituting (37) and (38) into the right-hand side of (31), I obtain

$$
\frac{\beta^{2} \delta^{2}(1+\delta) w^{2}(1+\beta \delta-m \delta(1-\beta))}{\left(1+\beta \delta+\beta \delta^{2}\right)\left(\left(1+\beta \delta+\beta \delta^{2}\right) A p_{t}-\beta \delta^{2} w\right)},
$$


where $\left(1+\beta \delta+\beta \delta^{2}\right) A p_{t}-\beta \delta^{2} w$ is positive from Lemma 1. Therefore, (D.1) implies that young naifs, except those of the initial-generation, do not fall into bankruptcy if and only if (44) holds.

\section{Appendix E Uniqueness of no-bankruptcy equilibrium}

Although I focus on the case $p_{t+1}^{t, t}>p_{t+1}$ in the text, I need to show that the case $p_{t+1}^{t, t} \leq p_{t+1}$ does not exist.

Suppose that $p_{t+1}^{t, t} \leq p_{t+1}$. I then have $R_{t}=p_{t+1} / p_{t}$. In this equilibrium, young naïfs do not have any assets; and the others have all the assets. The expected asset price is given by

$$
p_{t+1}^{t, t}=\frac{\beta \delta(1+\delta) w p_{t}}{\left(1+\beta \delta+\beta \delta^{2}\right) A p_{t}-\beta \delta^{2} w} .
$$

Note that (E.1) is the same as (35). I can, in turn, compute the future asset price

$$
p_{t+1}=\frac{\beta \delta(1+\delta) w}{\left(1+\beta \delta+\beta \delta^{2}\right) A}\left(1+\frac{\beta \delta}{1+\beta \delta} \frac{\beta \delta(1+\delta) w}{\left(1+\beta \delta+\beta \delta^{2}\right) A p_{t}-\beta \delta^{2} w}\right) .
$$

By mathematical induction, $p_{t}$ also ensures, from (B.5), (B.6), and (E.2), that $p_{t+1}>\beta \delta(1+\delta) /\left(1+\beta \delta+\beta \delta^{2}\right) A$. Finally, I take the difference between (E.1) and (E.2) to obtain

$$
p_{t+1}-p_{t+1}^{t, t}=-\frac{\beta \delta(1+\delta) w}{\left(1+\beta \delta+\beta \delta^{2}\right) A p_{t}-\beta \delta^{2} w} \frac{\beta \delta^{2} w(1-\beta)}{(1+\beta \delta)\left(1+\beta \delta+\beta \delta^{2}\right) A}<0
$$

which contradicts the hypothesis $p_{t+1}^{t, t} \leq p_{t+1}$. Therefore, I conclude that $p_{t+1}^{t, t} \leq$ $p_{t+1}$ does not exist. 


\section{Appendix F The bankruptcy equilibrium solution}

Using the same argument as in Appendix A, I can also derive the borrowing/lending behavior of sophisticates in bankruptcy equilibrium as follows:

$$
\begin{aligned}
s_{S, t, t} & =\frac{\beta \delta(1+\delta) w}{1+\beta \delta+\beta \delta^{2}}, \\
s_{S, t, t+1} & =\frac{\beta(1+\delta)}{1+\beta \delta} \frac{\beta \delta^{2} w \rho_{t}}{1+\beta \delta+\beta \delta^{2}} .
\end{aligned}
$$

Note that young naïfs' saving is the same as (F.1) and the middle-aged naïfs' saving is zero. By substituting (F.1), (F.2), $s_{N, t, t+1}=0$, and (52) into (20), I obtain (53).

\section{References}

[1] Barro, Robert J. 1999. "Ramsey meets Laibson in the neoclassical growth model." The Quarterly Journal of Economics, 114(4): 1125-1152.

[2] Gabrieli, Tommaso, Sayantan Ghosal. 2011. "Non-existence of competitive equilibria with dynamically inconsistent preferences." Economic Theory, Online First (DOI: 10.1007/s00199-011-0623-9).

[3] Heidhues, Paul, Botond Kôszegi. 2010. "Exploiting naïvete about self-control inthe credit market.” American Economic Review, 100(5): 2279-2303.

[4] Kiyotaki, Nobuhiro, John Moore. 1997. "Credit cycles.” Journal of Political Economy, 105(2): 211-248.

[5] Krusell, Per, Bruhanettin Kuruşçu, and Anthony A. Smith, Jr. 2002."Equilibrium welfare and government policy with quasi-geometric discounting." Journal of Economic Theory, 105(1): 42-72. 
[6] Laibson, David. 1997. "Golden eggs and hyperbolic discounting." The Quarterly Journal of Economics, 112(2): 443-478.

[7] Luttmer, Erzo G. J, Thomas Mariotti. 2003. "Subjective discounting in an exchange Economy." Journal of Political Economy, 111(5): 959-989.

[8] Meier, Sthephan, Charles Sprenger. 2010. "Present-biased preference and credit card borrowing." American Economic Journal: Applied Economics, 2(1): 193-210.

[9] O’Donoghue, Ted, Matthew Rabin. 1999. "Doing it now or later.” American Economics Review, 89(1): 103-124.

[10] O'Donoghue, Ted, Matthew Rabin. 2001. "Choice and procrastination." The Quarterly Journal of Economics, 116(1): 121-160.

[11] Samuelson, Paul A. 1958. "An exact consumption-loan model of interest with or without the social contrivance of money." Journal of Political Economy, 66(6): 467-482.

[12] Sorger, Gerhard. 2007. "Time-preference and commitment." Journal of Economic Behavior \& Organization, 62(5): 556-578.

[13] Tirole, Jean. 1985. "Asset babbles and overlapping generations." Econometrica, 53(6): 1499-1528.

[14] Wong, Wei-Kang. 2008. "How much time-inconsistency is there and does it matter? Evidence on self-awareness, size, and effect." Journal of Economic Behavior \& Organization, 68(3-4): 645-656. 


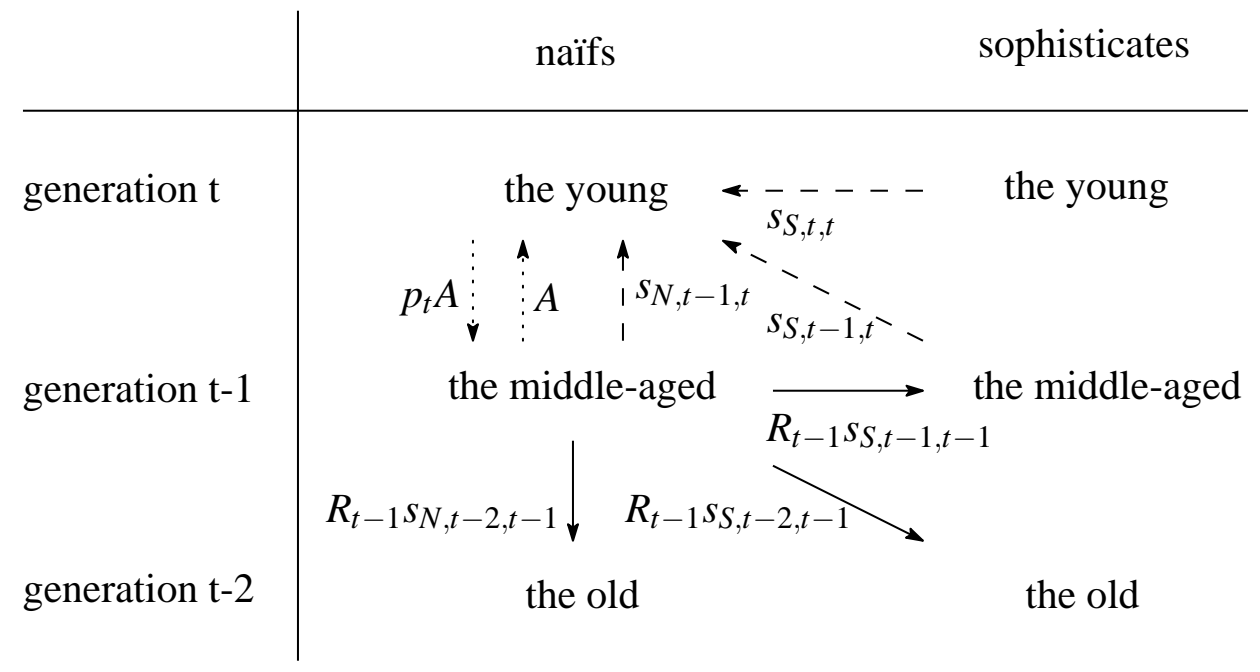

Figure 1: Asset transactions and loan contracts. The dashed arrows represent naïfs' borrowing and the solid arrows represent naïs' repayment. The dot arrows represent asset transactions. 


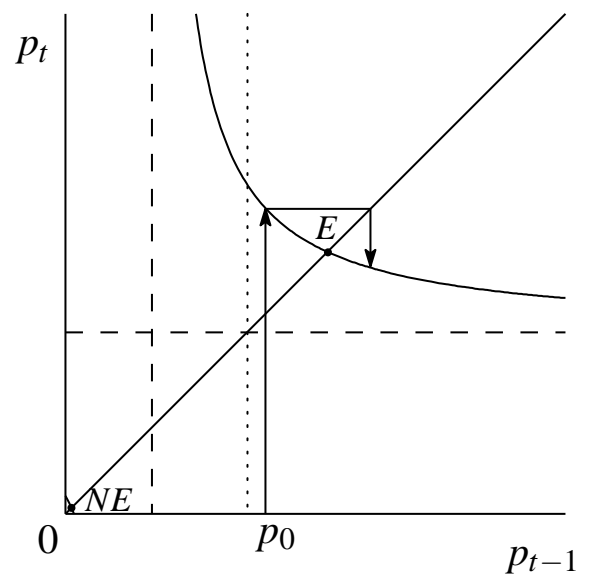

Figure 2: Dynamics of asset price in no-bankruptcy equilibrium. The dashed lines represent the asymptote of (36). The dotted line represents the lower bound of the asset price. The upper-right intersection $\mathrm{E}$ is the stable steady state, and the bottom left one NE is the unstable steady. The parameter is set at $(\beta, \delta, A, w)=$ $(0.9,0.9,1,6)$. 


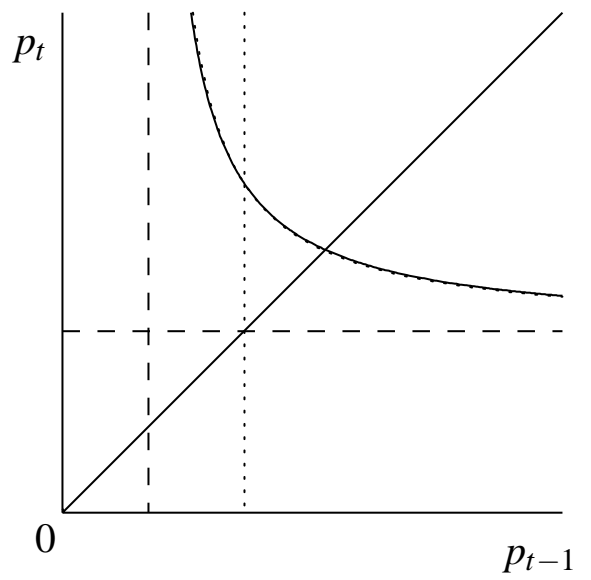

Figure 3: Dynamics of asset price in bankruptcy equilibrium. The solid curve represents the dynamics of asset price in bankruptcy equilibrium. In contrast, the dotted curve represents the dynamics of asset price in a no-bankruptcy equilibrium. The dashed lines represent the asymptote of (53). The dotted line represents the lower bound of the asset price. The upper-right intersection is the stable steady state, and the bottom left one, which is not visible in the graph, is the unstable steady state. The parameter is set at $(\beta, \delta, A, w, m)=(0.9,0.9,1,6,100)$. 